\title{
'ASYMMETRICAL RELATIONS IN AUDIOVISUAL TRANSLATION IN BRAZIL: A CORPUS-BASED INVESTIGATION OF FIXED EXPRESSIONS
}

\author{
Domingos Soares $^{1^{*}}$ \\ ${ }^{1}$ Universidade Federal de Santa Catarina, Florianópolis, Santa Catarina, Brasil
}

\begin{abstract}
This study aims to investigate, in dubbed and subtitled versions of the films Madagascar (2005) and Ice Age (2002), how fixed expressions (Moon, 1998) are translated in dubbing and subtitling methods and to examine how employing domestication and foreignisation (Venuti, 1995) can undermine or reinforce the asymmetrical relations, here defined by globalisation as discussed by Venuti (1998) and Cronin (2003, 2009). The analysis is carried out through reference and parallel corpus (Baker, 1995). Final results show that subtitling, rather than dubbing, is more prone to adopt foreignising strategies with regard to the translation of fixed expressions. Additionally, there have been identified, in the subtitled versions of the corpus, translation instances that deliberately move away from target language fixed expressions.

Keywords: Asymmetrical Relations; Domestication and Foreignisation; Fixed Expressions; Audiovisual Translation; Corpus-based Translation Studies
\end{abstract}

\footnotetext{
* PhD student at Universidade Federal de Santa Catarina (Brazil), in the English Graduate Program, with focus on Translation Studies. He holds an MA in the same program. His main research interests involve Audiovisual Translation, Transmedia Translation, Translator Education and Corpus-based Translation Studies. He is a member of the TRACOR (Translation and Corpora) research group. He has experience in teaching English as a Foreign Language and is a freelance translator. Email: domingosoares@gmail.com. ORCID: https://orcid. org/0000-0002-8344-7945.
} 
One of the most popular forms of entertainment, watching films is a complex activity with interpretative and sociocultural facets. Subtitling and dubbing share the position of audiovisual translation methods more traditionally employed (O’Connell, 1998; González, 2009). Applied in Brazil since the 1960s, subtitling was said to be the "preferred mode of translation both in cinema and on cable television" (Araújo, 2004, p. 199) in the country. Notwithstanding, audience preference has recently shifted. Carried out in 2014, a survey about the domestic preference for translation method reveals that 59\% of filmgoers preferred dubbed copies, whereas 23\% favour subtitling (Genestreti, 2015). The second survey included preference for Brazilian productions, which comprises $13 \%$ of filmgoers. In addition to being informative of the audience's increasing preference for dubbing, data are revealing of the ancillary prestige enjoyed by domestic films. If on one hand Brazilian filmic productions are in general not particularly prestigious in the domestic market, on the other, the Brazilian market does not display as much diversity in terms of origin of productions. All non-Brazilian films that figure in the Brazilian top 50 list ("Lista de filmes de maior bilheteria," 2019) of public attendance of all times are American productions (or coproductions). In a landscape of exchange of cultural products where maximising profit is imperative, expanding potential markets involves dominating media markets on a global scale. In this sense, globalisation comes about by uneven transactions establishing asymmetrical relations.

According to Venuti (1995), asymmetrical relations between countries affect the way translation is carried out by the use of particular strategies, tending towards domestication, which privileges target language and culture, and foreignisation, which privileges source language and culture. The asymmetry in the relationship between countries has a counterpart in the differences between distinct linguistic and cultural systems. Such linguistic inequalities maybe evidenced depending on the sort of text to be translated. That is the case of films that are permeated by linguistic and cultural elements of a particular language. These elements can be one word only. However, when they are labelled as word strings they form conventionalised multi-word units, for example: safe and sound, every man for himself, on behalf of. Fixed Expressions (Moon, 1998), as these multi-word units are called, are to a certain extent typical of a given language, both in composition and meaning, and, as such, distinct languages might present fixed expressions composed by different words or even that bear no correspondence in meaning or use.

On the basis of what has just been mentioned, this study proposes to analyse the rendition of fixed expressions (Moon, 1998) in audiovisual translations of the animated films Madagascar (2005) and Ice Age (2002) taking into account the asymmetrical relations, which in this research are manifested in centrifugal and centripetal forms of globalisation (Cronin, 2009) at the contextual level, and textually manifested in Venuti's (1995) notions of domestication and foreignisation. The analysis is carried out by means of reference and parallel corpora (Baker, 1993). The translations of fixed expressions are analysed by using Baker's (2011) strategies to translate fixed expressions aligned with the notions 
of foreignisation and domestication (Venuti, 1995). By privileging source or target language conventions, translation strategies that domesticate or foreignise fixed expressions are seen as a means to respectively undermine or reinforce the asymmetrical relations. The relation between globalisation and translation is further explored in the next section.

\section{Asymmetrical Relations}

Giddens (1990) defined globalisation as "the intensification of worldwide social relations which link distant localities in such a way that local happenings are shaped by events occurring many miles away and vice versa" (1990, p. 64). In a globalised context, the distance that sets individuals apart and has a defining role in the identification with their cultural setting is shortened by the immediateness in the interaction yielded by technological advancements. As borders fade, a lingua franca arises and challenges the use of vernaculars and, consequently, the need for translation. Conversely, as Cronin (2003) puts it, "globalization has not meant the demise of translation as an activity but, on the contrary, late modernity has witnessed an explosion of demand for translation" (p. 34). The intensification in the production of translations might signal to some diversity in the global flow of media exchange as well as the maintenance of linguistic diversity. Despite the fact that globalisation reassures the maintenance of linguistic diversity by the intensification of translation, the presence of a dominant lingua franca is made evident in the choice of English "as source or target of 75.12 per cent of all translation acts" (Bellos, 2011, p. 125). If, on one hand, globalisation does not necessarily result in the complete disappearance of the world's languages, on the other, it has contributed to the overt presence of the English language. This asymmetry is enhanced depending on the language English measures its power against, and especially on the type of media transacted, as is the case of American films in Brazil.

From a general perspective, at the core of the interplay between globalisation and translation lies the tension between two forms of globalisation: centripetal and centrifugal globalisation (Cronin, 2009). The centrifugal form implies that globalisation results in interdependence, hybridity, syncretism, crossover and creolisation. From this perspective, translation "allows speakers of a language under threat to retain full autonomy" (p. 128), thus preserving their own language. Conversely, the centripetal form of globalisation, the notion of globalisation as homogenisation, is associated with imperialism, hegemony, subjection, Westernisation and Americanisation. Translation is seen as "the sine qua non of the cultural dominance and an agent of centripetal globalisation if we consider that without the services of dubbers and subtitlers Hollywood dominance of global cinema markets would be inconceivable" (p. 128). If translation operates actively in centrifugal and centripetal forms of globalisation, the strategy adopted in a particular translation instance manifests its tendency towards one or the other pole. According to Venuti (1995), in rendering a foreign text into a 
domestic language, translational choices tend to vary on a continuum: on one end, the translation retains linguistic and cultural traces of the source text (i.e. foreignising translation); on the other, it seeks to hinder such features, producing a translated text that abides by the conventions prevailing in the target language and culture (i.e. domesticating translation).

On account of the economic (exchange and reception) and cultural (prestige) asymmetry in the exchange of films between the USA and Brazil, a foreignising translation makes English-language typical features visible in the Brazilian translation. It presents a Brazilian Portuguese in the semblance of the world's lingua franca, producing a homogenising version of the language. Foreignising translation is here considered as a manifestation of centripetal globalisation. Conversely, adopting a domesticating translation implicates the maintenance of Brazilian Portuguese standards. By preserving the target language in an asymmetrical translational relation, this strategy is considered closely related to the centrifugal form of globalisation. In the present study, Fixed Expressions is the linguistic unit selected given their potential to meaning specificity, which can bestow on them some degree of typicality, and their multi-word compositions, a challenge for audiovisual translation.

\section{Fixed expressions}

Language is a "crucial mechanism contributing to the formation and reinforcement of a cultural identity" (Cowie, 1998, p. 9). Words are the most elementary linguistic units. They evoke meaning in the mind of the user, however superficial or decontextualised this meaning can be if a word is presented alone. All the same, by combining words new possibilities for meaning are created. That way, the stock of possibilities to compose new meanings is stretched beyond the limitation the unitary word meaning imposes. Individual lexical items tend to come together in particular combinations so as to form larger units. This complex unit can convey meanings that differ from the overall combination of all individual words. Moon (1998) calls these word strings fixed expressions (henceforth FEs).

As Moon (1998) puts it: "[f]ixed expression is a verygeneral but convenient term, (...) used to cover several kinds of phrasal lexeme, phraseological unit, or multi-word lexical item: that is, holistic units of two or more words" (p. 2). As the basic criterion for identifying FEs, non-compositionality in its tripartite dimensions, namely semantics, lexico-grammar and pragmatics, form the macrocategories of FEs proposed by Moon (1998): anomalous collocations, formulae and metaphors. Apart from the specificities each FE has in its composition, the relationship between a given signified and its FE-signifier may also be typical of a given language. As FEs are formed by the unique juxtaposition of particular words, they are capable of creating linguistic labels that are potentially typical in composition, usage and meaning. "[C]onventional ways of saying things often seemed to reflect, and also promote, particular ways of thinking about 
experience" (Lee, 2007, p. 472). From the point of view of the language user, the accurate use of FEs is indicative that the people involved in the communication situation are sensitive to the standards of fixation in that particular language. As a result, the use of FEs reflects in the identification between individuals, for it transmits "insider knowledge", functioning as "social bonding" (Wray, 2009). The particularity in the formulation of FEs is often seen in terms of its close connection with culture and linguistic identity. FEs are then seen as culturebound terms, that is, as lexical evidence of the particularity of a given language/ culture. From that perspective, FEs can be understood with regard to not only the possible specificity of the culture they stand for, but also to some degree to the uniqueness in linguistic formulation, which can be challenging to translate.

No two languages are equal. Even though some languages may have similar origins and, therefore, present chiefly equivalent uses for particular words, the cross-linguistic equivalence in the meaning of these words is jeopardised by the way they are used. FEs are considered linguistic conventionalities (Tagnin, 2005). The implication that this has to translation lies in the supposed inequality of the conventionalities different languages present. Conversely, the proximity of two languages may be reflected in the phrasing and meaning, or use, attributed to particular FEs. Colson (1998) points to a "common idiomatic heritage to all European languages, originating from biblical or Latin and Greek expressions" (p. 193). Therefore, American English and Brazilian Portuguese might share, to a certain extent, some similarity in FEs. The degrees in the (dis)similarity in FEs across languages can vary from full correspondence in phrasing and meaning to the total lack of a similar lexical convention (Baker, 1992).

Apart from having to cope with general constraints, the translation process of FE should keep a watchful eye on how an integral part of the social context they are, on account of the linguistic-cultural differences in the pair and, in the case at hand, because of the translation limitations imposed by the audiovisual translation methods.

\section{Audiovisual Translation}

In addition to the dissimilar fixation patterns across any language pair, the rendering of FEs in an audiovisual environment poses an extra challenge, as a result of the dissimilarities between the resources available to the original production and the resources available to operationalise the translation. Filmic meaning is conveyed through two channels, the visual and the acoustic, but language transfer is carried out essentially on the verbal information contained in each of the channels. As componential parts of the film, facial expressions, scenery and background noise, to cite a few elements, are not commonly changed in the translation, which in turn must be shaped with the aim to conform to the meanings fashioned by them. That way, the polysemiotic filmic nature (Chiaro, 2009) restrains possibilities for translation, conditioning them. Audiovisual materials are mainly translated using two methods: subtitling and dubbing, 
(O’Connell, 1998; González, 2009): each of which has its own specificities, constraints and potentialities.

To begin with, "subtitling can be defined as the process of providing synchronized captions for film and television dialogue" (Shuttleworth \& Cowie, 1997, p. 161). The process underlies several technicalities: spatial limitations, as the viewer needs to cope with reading both images and words, the subtitles are generally placed horizontally with a maximum number of characters; temporal limitation, a particular subtitle instance should be exposed for a time length similar to that of the utterance; text reduction entails a reduction in text length because of the interplay between spatial and temporal aspects. Depending on the speed with which an utterance is spoken much can be conveyed within a short time length. Because of these technicalities, complete, detailed rendering is not always feasible. (Díaz Cintas \& Remael, 1997).

According to Luyken et al (1991), dubbing is a process that consists of "the replacement of the original speech by a voice track which attempts to follow as closely as possible the timing, phrasing and lip-movements of the original dialogue" (p. 144). In dubbing, synchronicity - chiefly called lip-sync - is the most challenging issue. According to Shochat and Stam (1985), "[t]his matching is diversely articulated with specific cinematic codes such as angle, scale, lighting and so forth, with exigencies varying according to whether a shot is close-up or plan américain, profile or frontal, well or dimly lit" (p. 49). Because of the necessity of synchronicity, the dubber's task involves articulating both meaning and lip movement. However, the whole composition of the image affects directly the degree of constraint to obtain a satisfactory rendering: the closer the shot the higher the necessity of correspondence between sound and lip movement.

The intrinsic differences in the support that subtitling and dubbing give to the comprehension of verbal language in films ground the reasons for preference for one method over the other. As a process that involves the merged comprehension of written text and audiovisual elements, subtitling is relatively more cognitively demanding if compared to dubbing. "[S]pectators actually read films as much as they see and hear them, and the energy devoted to reading subtitles inevitably detracts from close attention to images and sounds" (Shochat \& Stam,1985, p. 48). The ability to cope with the more complex polysemiotic nature of a subtitled film is directly proportional to the viewer's degree of literacy. In contrast, dubbing "reduces the amount of processing effort required on the part of the audience and makes (it) the most effective method to translate programmes addressed at children" (González, 2009, p.17). Therefore, subtitled films are more appropriately followed by those who have higher literacy skills. Such ability might be an element contributing to the fact that "subtitling is often preferred by more educated audiences" (O'Connell, 2007, p. 128). Another relevant element to this end is that subtitling preserves a film's original dialogue, thus allowing for direct access to the source language. One more aspect contributing to the preference for either subtitling or dubbing concerns their budgets. In Countries where the 
population, and therefore the audience, is smaller subtitling is usually adopted. Conversely, large, more economically powerful countries use dubbing for it is potentially more appealing and therefore less economically risky. (Shuttleworth \& Cowie, 1997; Linde \& Kay, 1999). Conversely, Danan (1991) states that American domination of early filmic production caused great European countries to create protectionist measures to guarantee local linguistic and cultural hegemony. These measures included precise quotas to imported films and demanded that these films were dubbed, rather than subtitled.

Notwithstanding, associatingsubtitling with foreignisationanddubbingwith domestication cannot be done unproblematically. Pavesi (2008) explains that "the permeability of the source text in audiovisual translations has been amply demonstrated by the calques which have been reported to occur systematically in dubbing and subtitling in various target languages" (p. 91). Considering that both subtitling and dubbing are then inevitably foreignising to a certain degree, investigating FEs in audiovisual translation in this study consists of scrutinising which AVT method, dubbing or subtitling, tends towards Cronin's (2009) centrifugal globalisation (manifested in domesticating translation strategies) or centripetal globalisation (manifested in foreignising translation strategies), thus undermining or reinforcing the asymmetrical relations. Next, the methodological steps taken to scrutinise the renditions of FEs in the corpus selected are presented.

\section{Method}

To carry out the linguistic analysis of both source and target texts, this research relies on tools and concepts introduced by Corpus-based Translation Studies. Corpora are large sets of authentic, machine-readable texts selected in a principled way (Bowker \& Pearson, 2012). For the purpose of this study, I use two types of corpora to the following ends: (i) reference corpus (Baker, 1995) aid in the identification of FEs present in source texts in the cases dictionaries or glossaries do not prove sufficient to accomplish such a task; (ii) parallel corpus (Baker, 1995) provide swiftness and improve consistency to the analysis of the translation strategies adopted. This is particularly convenient for the present study because the corpus under investigation amounts to 6 dialogue lists:

- 2 lists of source dialogues comprising of 1879 types and 12821 tokens in total;

- 2 lists of dubbed dialogues comprising of 2268 types and 12212 tokens in total; and,

- 2 lists of subtitled dialogues comprising of 2249 types and 9660 tokens in total. 
The corpus has been selected to represent films seen by as wide a fraction of the Brazilian audience as possible. The films selected share the following aspects: they have sequels, which indicates the success of the original production; they have been telecasted (more than once), which raises the possibility for an even broader reception; they are entertainment for families, their target audience is simultaneously children and adults.

The initial analytical step involved identifying the FEs in the source-text portion of the corpus. In order to do so, I read each of the sentences in the source texts and identified potential candidates for FEs based on Moon's criterion of non-compositionality. In order to confirm their status as FEs, firstly I resorted to online dictionaries and glossaries. ${ }^{1}$ When this proved insufficient, I resourced to the Corpus of Contemporary American English (Davies 2008-) (henceforth referred to as COCA) to assess the candidates for FEs As there is no large reference corpus for Brazilian Portuguese, Webcorp (a suite of tools that uses the internet as a corpus) is used to aid in the identification of target language FEs. A second analytical procedure, necessary for the purposes of the present study, is to identify the presence of domestication and foreignisation in the renditions of FEs in the corpus investigated. Microsoft ${ }^{\bullet}$ Excel was an at-hand alternative to deal with the threefold parallel corpus under investigation. Whenever it was necessary to verify the interplay between words and images, I used the software Subtitle Workshop 6.0b.

For practical purposes, Venuti's (1995) notions of domestication and foreignisation have been refined based on Baker's (2011) strategies to translate FEs and Tagnin's (2005) concept of conventionality. As has been previously discussed, FEs are culture-bound language instances that are somewhat typical of a given language/culture and conventionalised by use (Tagnin, 2005). What is at stake in an AVT context of asymmetrical relations is the way FEs, as conventional instances of source language/culture, are presented in the target texts. Particular renderings are considered to domesticate or foreignise on the grounds of the conventionality they retain: domestic conventionality (strategies that use FEs in the target text, with similar or dissimilar wording); no conventionality (translation by paraphrase or omission -strategies that deal with FEs in a compositional fashion), or foreign conventionality (borrowings). Considering that preserving domestic, culture-bound language can be a means to undermine the asymmetrical relations, in practical terms, this tripartite distinction embodies degrees of proximity to or separation from domestic conventionality. This implies that zero-conventionality renderings are considered domesticating translations because they avoid foreignisation rather than because they abide by target language conventions; that is, they present domestic wording but as a compositional string (in opposition to the FE holism). The discussion of the data in the following section departs from the most noticeable tendencies in the use of translation strategies in the way they abide by conventionality. 


\section{Dubbing X Subtitling in the Films: tendencies, whys and wherefores}

In overall figures, 79 tokens of FEs have been identified in the source texts. The diagram below shows the distribution of strategies to translate FEs according to the way they retain conventionality in dubbed and subtitled versions.

Figure 1. Overall Tendencies

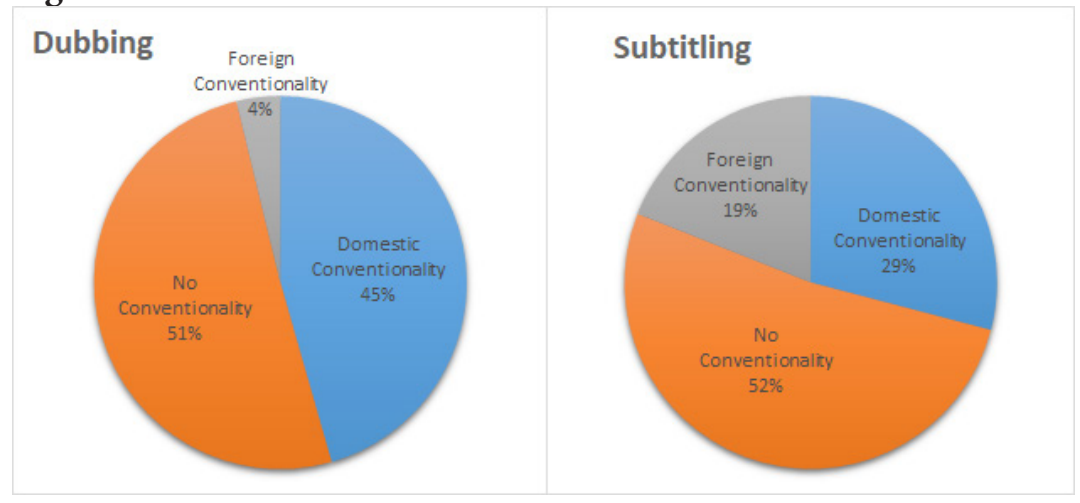

Dubbing and subtitling display similar frequency of source language FEs that are translated resorting to no conventional wording; $51 \%$ and $52 \%$ respectively. This balance allows us to focus on the role conventionality plays in the corpus. Even though domestic conventionality is more abundant than foreign conventionality in both translation methods, subtitling is revealed as notably more prone to adopt foreignisation than dubbing. Foreignisation is the option adopted in 19\% of the subtitled versions of FEs in the corpus, whereas dubbed ones deal with FEs in this fashion in $4 \%$ of the occurrences. The proportion of foreignisation in subtitling is nearly five times higher than in dubbing. Even though the frequency in the adoption of foreignising translations in subtitling is not high enough to overshadow the frequency of domestic conventionality, foreignisation is much more frequent in subtitling than in dubbing. Conversely, dubbing adopts foreignisation at a lower rate and it adopts domestic conventionality more often than subtitling does. This arrangement has severe contextual implications. On the basis of the argument supported in this study, strategies that resemble foreignisation (Venuti, 1995) to translate FEs from a central language into a less central one affect the intercultural contact by presenting source language linguistic-cultural conventionality in translated films.

Apart from the overall figures, the nature of the FEs and the translational and contextual conditions that might bring them about, examining the general tendencies in more detail can elucidate the raison dêtre of the state-of-affairs in the intercultural exchange under scrutiny. In order to shed light on what might have motivated such overall tendencies, let us first examine the cases in which both audiovisual translation methods deal with conventionality in a similar fashion. That is, let us focus on the instances of FEs when both dubbing and subtitling retain domestic conventionality. 


\section{When Dubbing and Subtitling Domesticate}

Out of the 79 tokens of FEs identified, there are 18 cases in which both audiovisual translation methods retain domestic conventionality. Moreover, both methods domesticate with similar wording in 13 of them. Some of them are in fact (translated as na verdade), how about (translated as que tal), you know what? (translated as sabe de uma coisa), leave me alone (translated as me deixa em paz), and take care of it (translated as dar um jeito). The fact that similar translational solutions are adopted in both methods comes as no surprise since (i) two languages may present similar fixation patterns depending on the degree of their shared origins (Colson, 2008), and (ii) FEs are preferably translated as FEs (Baker, 2011). Owing to space constraints, the account herein presented focuses on the cases in which FEs are translated so as to abide by domestic conventionality but that are differently dealt with in dubbed and subtitled versions. The translations of FEs that retain domestic conventionality with different translation solutions are listed below.

Table 1 - Dubbing and Subtitling domesticate using different translation solutions

\begin{tabular}{|l|l|l|l|}
\cline { 2 - 4 } \multicolumn{1}{l|}{} & Source Text & Dubbed Version & Subtitled Version \\
\hline 1 & Nice work, Melman. & Mandou bem, Melman. & Bom trabalho, Melman. \\
\hline 2 & Beg your pardon? & Como disse? & Como é? \\
\hline 3 & $\begin{array}{l}\text { Don't bite the hand that } \\
\text { feeds you. }\end{array}$ & $\begin{array}{l}\text { Não se cospe no prato em } \\
\text { que se come. }\end{array}$ & $\begin{array}{l}\text { Não se morde a mão que } \\
\text { te alimenta. }\end{array}$ \\
\hline 4 & Give me a break. & Dá um desconto. & Dá um tempo. \\
\hline 5 & $\begin{array}{l}\text { Would you give a guy a } \\
\text { break? }\end{array}$ & Dá pra dar um tempo? & Pega leve comigo. \\
\hline
\end{tabular}

In all cases, different translation solutions also entail resorting to a domestic FE of (slightly) different meaning but similar effect. In the first case (line 1, table 1), both renditions are means to complement and reinforce Melman's behaviour. On one hand, the subtitled version maintains source text wording, whereas dubbing resorts to a more informal $\mathrm{FE}$ in the target language. By resorting to written and oral language respectively, subtitling and dubbing are accordingly affected by the need to consider register. In contrast, the dubbed rendition in line 2 seems to be selected as a means to emulate source text formal use of the $\mathrm{FE}$ in this case (in the context the main characters have been fighting and are not on good terms). The subtitled rendition tends to neutralise register marking by using a shorter rendition that is also closer to spoken language.

The proverb in line 3 has the function to teach not to show ingratitude. Its dubbed and subtitled versions have similar functions, but the dubbed version translates as a proverb whose focus lies on the ingratitude itself in spite of the layer of aggression source and subtitled versions depict. In subtitling, this difference seems to have been motivated by the character's gesture in the moment of the 
utterance, as the scene the character is clearly referring to his hand. The dubbed rendition could have discredited the visual channel and focused on producing a rendition that ignores the potentially violent aspect in the source dialogue - that is uttered by a character who is a lion - in order to mitigate the violence presented to the audience, which is also composed of children.

In lines 4 and 5, the polysemic give someone a break conveys, respectively, the request to stop criticism and the request for a pause in one's work or activities. The dubbed rendition in line 4 implies not being so rigid and allows forbearance, whereas the string in the subtitled version corresponds to its source language counterpart in wording and meaning. Despite the availability of a shorter FE in the target language, the dubbed version prefers a more opaque rendering that has a jesting effect even at risk of dropping lip synchronicity quality (syllable count in this dubbing rendering is shorter than the alternative used in subtitling). The subtitled version in line 5 is more colloquial than its dubbed counterpart. This rendition has apparently been motivated by the subtitling technicality of text reduction; it is, for example, 4 characters shorter than dubbed rendition and 4 words shorter than source dialogue. The dubbed rendition, in this case, seems to be motivated by the interplay between verbal language and visual channel; in the scene the character in the foreground pleas for a break, the one in the background (top right corner) is holding a clock, as though offering him the break for which he asks. The pun between image and words is maintained in dubbed by the use of an equivalent FE that contains the word tempo (time).

More remarkably in the cases discussed in lines 1, 3 and 4, subtitling abides by domestic conventionality retaining the shared patterns of fixation in the language pair. Dubbing, on the other hand, seems to resort to translation solutions other than the unchallenging use of well-justified quasi-literal translation. The next nexus explored entails foreignisation in both methods.

\section{When Dubbing and Subtitling Foreignise}

Differently from the numerous occurrences in the previous section, the limited cases in which dubbing foreignises FEs make examining its juxtaposition with subtitling fully feasible: there are only 2 occurrences.

Table 2 - Dubbing and Subtitling Foreignise

\begin{tabular}{|l|l|l|l|}
\cline { 2 - 4 } \multicolumn{1}{c|}{} & Source Text & Dubbed Version & Subtitled Version \\
\hline 1 & $\begin{array}{l}\text { Ladies and gentlemen, } \\
\text { children of all ages, the } \\
\text { Central Park Zoo proudly } \\
\text { presents: }\end{array}$ & $\begin{array}{l}\text { Senhoras e senhores, cri- } \\
\text { anças de todas as idades, o } \\
\text { Zoológico Central Park de } \\
\text { Nova York, tem o prazer de } \\
\text { apresentar: }\end{array}$ & $\begin{array}{l}\text { Senhoras, senhores, cri- } \\
\text { anças de todas as idades, o } \\
\text { Zôo apresenta: }\end{array}$ \\
\hline 2 & Yeah, well, you know... & É, bom, você sabe... & Bem, você sabe... \\
\hline
\end{tabular}


A search for strings similar to those on dubbed and subtitled versions in line 1 yielded no results on Webcorp. The Brazilian Portuguese FE is composed of fewer lexical items: Senhoras e senhores only. The use of foreignisation strategy is not justified in any AVT technicality. Subtitled rendering, even if constrained by temporal dimension (being forced to produce a line long enough to match the time of utterance), could have maintained target language conventionality by suppressing 'children of all ages', or focused on 'the Central Park Zoo proudly presents' as a means to present a rendition whose length would match spoken utterance. The dubbed version, on its turn, is not limited by lip-sync - the technical need to synchronise translated utterance and lip movement. In this particular scene, the dialogue line is uttered through a loudspeaker, shown in the foreground. In every case, maintaining the reference to children in the translated texts can be a means to appeal to the public by directly addressing the child audience.

In line 2, you know is used as a filler. It is defined as: "used while you think about what to say next" ${ }^{2}$ and "something that you say while you are thinking what to say next". Source dialogue offers no information but wording functions similarly to fillers, as yeah, well. The option to foreignise in this case seems to be motivated by the lack of verbal formulations that carry actual information in the dialogue, which could serve as a basis for a different solution. As it follows, no linguistic or technical aspect interferes with translating source language FE as target language FE. It seems reasonable to attribute this rendition to the high degree of transparency of the FE.

All instances of foreignised FEs in dubbed versions are under the category of formulae. According to Moon (1998), formulae are "compositional strings that nevertheless have some special discoursal function" (p. 22); they are the most transparent category of FEs. Following this reasoning, Baker (2011) suggests that the more opaque a FE, the more likely a translator is to detect it as such. As a consequence, formulae transparency renders them less obviously noticed as FEs, which in turn enhances their chance of being foreignised. This is the first tendency identified: only formulae are foreignised by both dubbing and subtitling; dubbing only foreignises formulae. In the cases identified, both methods seem to foreignise primarily because of the transparent nature of this category of FEs.

\section{Dubbing and Subtitling: Crossing Conventionalities}

In addition to the tendencies that can be acknowledged by comparing and contrasting general proportions, the ways FEs are dealt with in subtitling and dubbing can be cross-examined with the uses of strategies that enclose either source or target language conventionality, trying to establish patterns in similar/ alternative renderings to particular occurrences of FEs in the source films. The following tendencies identified in the study are a result of combining the different ways to represent FE conventionality (i.e. domestic conventionality, no conventionality, and foreign conventionality) to translate the same source 
language FEs. It results in the following combinations of crossings, (listed from A to $\mathrm{F}$ in figure 2 below)

Figure 2 - Crossings in Conventionalities

\begin{tabular}{|c|c|c|c|}
\hline \multicolumn{3}{|c|}{ Venuti's (1995) Domestication } & \multirow{2}{*}{$\begin{array}{c}\text { Venuti's (1995) Foreignisation } \\
\text { Foreign } \\
\text { Conventionality }\end{array}$} \\
\hline \multicolumn{2}{|c|}{$\begin{array}{c}\text { Domestic } \\
\text { Conventionality }\end{array}$} & $\begin{array}{c}\text { No } \\
\text { Conventionality }\end{array}$ & \\
\hline A & Dubbing & Subtitling & \\
\hline \multirow[t]{2}{*}{ B } & Dubbing & & Subtitling \\
\hline & & Dubbing & Subtitling \\
\hline D & Subtitling & Dubbing & \\
\hline \multirow[t]{2}{*}{$\mathrm{E}$} & Subtitling & & Dubbing \\
\hline & & Subtitling & Dubbing \\
\hline
\end{tabular}

The figure represents:

A. Occurrences when dubbing adopts domestic conventionality and subtitling adopts no conventionality;

B. Occurrences when dubbing adopts domestic conventionality and subtitling foreignises;

C. Occurrences when dubbing adopts no conventionality and subtitling foreignises;

D. Occurrences when subtitling adopts domestic conventionality and dubbing adopts no conventionality;

E. Occurrences when subtitling adopts domestic conventionality and dubbing foreignises;

F. Occurrences when subtitling adopts no conventionality and dubbing foreignises.

Crossings $\mathrm{A}$ and $\mathrm{D}$ involve the broadest proportions of occurrences in the corpus (A -dubbing domestic conventionality 45\% X subtitling no conventionality 
52\%; D - subtitling domestic conventionality $29 \% \mathrm{X}$ dubbing no conventionality 51\%). Probably on that account, these particular crossings are not particularly revealing of any tendency that can help to shed light on what influences subtitling pull away from domestic conventionality. Crossings $\mathrm{E}$ and $\mathrm{F}$ are not frequent enough to influence overall tendencies. Differently, crossings B and C display clearer tendencies and are further explored next.

\section{Two degrees of separation: domestic conventionality in dubbing $X$ foreign conventionality in subtitling}

The most noticeable aspect concerning the crossing at hand is the fact that, except for the first occurrence in the table below, all FEs fall under Moon's (1998) category of formulae.

Table 3 - Domestic Conventionality in Dubbing X Foreign Conventionality in Subtitling

\begin{tabular}{|l|l|l|l|}
\cline { 2 - 4 } \multicolumn{1}{l|}{} & Source Text & Dubbed Version & Subtitled Version \\
\hline 2 & $\begin{array}{l}\text { In fact, without me, there } \\
\text { wouldn't even be a “you”. }\end{array}$ & $\begin{array}{l}\text { Na verdade, sem mim, } \\
\text { não teria nenhum “você”. }\end{array}$ & $\begin{array}{l}\text { De fato, sem mim, nem } \\
\text { haveria um “você”. }\end{array}$ \\
\hline 3 & That's it. & Já chega. & É isso. \\
\hline 4 & Nine lives, baby. & Sete vidas, menino. & See you later, crocodile. \\
\hline 5 & $\begin{array}{l}\text { No, seriously. Look at } \\
\text { you. Those ladies, they } \\
\text { don't stand a colega. }\end{array}$ \\
\hline 6 & $\begin{array}{l}\text { Não, é sério. Olha só } \\
\text { aquelas garotas. Elas não } \\
\text { vão resistir. }\end{array}$ & $\begin{array}{l}\text { Sério, olhe para você. } \\
\text { Aquelas moças estão } \\
\text { perdidas. }\end{array}$ \\
\hline
\end{tabular}

The FE in the first line is an Anomalous Collation, FEs that "are problematic in lexicogrammatical terms" (Moon, 1998, p. 20), and are usually not frequent in the English language at large. In fact is "used for saying what is really true, when this is surprising or different from what people think", ${ }^{4}$ which matches the dubbed rendition that is phrased with different wording. Conversely, the subtitled version retains source language composition even at the expense of changing its meaning; de fato is used in Brazilian Portuguese to confirm a previous statement. If used in subtitling, the longer rendition na verdade would be problematic on account of the spatial dimension constraint to subtitling.

Similarly, the FE in line 2, that's it, is "used when a series of situations has made you angry, so that you decide to leave or to stop what you are doing.". Its dubbed rendition, já chega, is a FE on an equal basis. The subtitled rendition, the string é isso, invariably requires complement, different from the way it is used in line 2 . This string is a rendition of the words composing the FE in the source language.

Likewise, the subtitled rendition in line 3 maintains source language wording but in the source language itself. The source FE is a play on words with 
the string see you later, alligator. According to The Free Dictionary, ${ }^{6}$ this string was in use especially in the South of the US since the 1930s. It became popular after the success of the homonymous song composed by Bill Haley. In the song, the string creates an adjacency pair with the answer after a while crocodile. The accurate use of FE serves to promote cultural bonding and is a sign of insider knowledge (Wray, 2009). By composing the string as see you later, crocodile, the character markedly conveys his position of partial ignorance and attempts to get closer to the culture of the individuals with whom he is interacting. The Brazilian Portuguese institutionalised formulae vai pela sombra (take a shadowy path) provides the basis to reproduce the playfulness in the source dialogue by replacing the conventional sombra (sombra) by chuva (rain). Subtitling not only eschews from reproducing the play on words as it also brings source language to the 'translated' dialogue.

Source dialogue in line 4 is uttered when the character Diego (a sabretoothed cat), who had been deadly wounded and surprises his companions by being well and healthy. He then reminds that cats have nine lives, implying they "can survive things that are severe enough to kill them". In the correspondent proverb in Brazilian Portuguese, ${ }^{8}$ however, cats have seven lives, instead of nine. It follows that the dubbed rendition abides by target language proverb whereas the subtitled version translates the proverb literally. Since sete (seven) and nove (nine) have the same quantity of characters, there is no apparent motivation as to why subtitled version adopts a foreignising strategy.

The string look at you, in lines 5 and 6, can be "used for telling someone that you are surprised or impressed by them". ${ }^{9}$ Its dubbed counterpart in both instances, olha só, is similarly used to express that one is impressed or surprised, but the cause of the surprise is not fixed and depends on the complement. Both dubbed versions adopt a domesticating strategy, with the dubbed rendition in line 5 changing the object of admiration. Conversely, the subtitled versions in lines 5 and 6 adopt renderings based on equivalent lexical items: in the first case, each lexical item is translated non-compositionally, in the second, the preposition to is not translated but the remaining lexical items are equivalent in the language pair. The particular instance of foreignisation in line 6 seems to be a result of subtitling tendency to text reduction because it is one (out of three) words shorter than its dubbed counterpart. Conversely, the subtitle rendition in line 5 cannot be explained by subtitling technicalities, since it is two characters longer than the equally available domestic $\mathrm{FE}$ olhe só você.

Crossing occurrences of compositional domestication and foreignisation exposed something complementary to the second tendency. If on one hand formulae are the only category of FEs to be foreignised in dubbing, on the other, they have also revealed noteworthy disparity between strategies in dubbed and subtitled versions. Another tendency is formulae are the majority of the FEs that dubbing fully domesticates and subtitling foreignises. Dubbing seems to be more likely to display linguistic conventionality in terms of pragmatics if compared to subtitling. In a context of asymmetrical relations, this implicates that domestic 
"stereotypical aspects of experience" that "perform a stabilizing function in communication" (Baker, 2011, p. 68) are more likely to be maintained in dubbing than in subtitling.

\section{One step away from domestic conventionality: no conventionality in dubbing $\mathrm{X}$ foreign conventionality in subtitling}

This section contrasts instances of translated FEs when dubbing moves towards subtitling foreignisation. All cases in this crossing are Metaphors.

Table 4 - No Conventionality in Dubbing X Foreign Conventionality in Subtitling

\begin{tabular}{|l|l|l|l|}
\cline { 2 - 4 } \multicolumn{1}{l|}{} & Source Text & Dubbed Version & Subtitled Version \\
\hline 1 & $\begin{array}{l}\text { When the New York giants } \\
\text { wake up, we will make } \\
\text { sure that they wake up in } \\
\text { paradise. }\end{array}$ & $\begin{array}{l}\text { Quando os gigantes de Nova } \\
\text { York acordarem vamos fazer } \\
\text { com que acordem no paraíso. }\end{array}$ & $\begin{array}{l}\text { Quando os gigantes de NY } \\
\text { acordarem queremos ter } \\
\text { certeza de que acordem no } \\
\text { paraíso. }\end{array}$ \\
\hline 2 & $\begin{array}{l}\text { I'm putting sloths on the } \\
\text { map. }\end{array}$ & $\begin{array}{l}\text { Colocando as preguiças na } \\
\text { história. }\end{array}$ & $\begin{array}{l}\text { Colocando as preguiças no } \\
\text { mapa. }\end{array}$ \\
\hline 3 & Any of this a-ringin' a bell? & $\begin{array}{l}\text { Isto não te lembra alguma } \\
\text { coisa? }\end{array}$ & Não soa familiar? \\
\hline 4 & $\begin{array}{l}\text { Now, he may be a pain in } \\
\text { the butt at times... }\end{array}$ & $\begin{array}{l}\text { Eu sei que às vezes ele } \\
\text { maltrata a gente. }\end{array}$ & $\begin{array}{l}\text { Ele até é "um dente na } \\
\text { bunda" de vez em quando... }\end{array}$ \\
\hline 5 & Pack of lies. & Bando de idiotas. & [Bando] De mentiras! \\
\hline 6 & Pack a wallop. & Bando de trochas. & [Bando] De pancadas! \\
\hline
\end{tabular}

The FE in line 1 implies to take "action so that you are certain that something happens, is true, etc". ${ }^{10}$ This particular denotation of make sure means causing something to happen. Dubbed rendition in line 1, the compositional string, fazer com que, in this context means to act in order to provoke the desired result to come about. Conversely, subtitled version in line 1, ter certeza, usually means to be certain and does not imply that action is to be taken in order to cause a particular result. Considering that it uses lexical items similar to the source text's $\mathrm{FE}$, it is a case of foreignising strategy. The subtitled versions in both lines invert the meaning of the FE in their renditions.

The metaphor put someone on the map, in line 2 means "to make a thing, person, or place famous". ${ }^{11}$ It is translated compositionally in both versions. The subtitled version, however, adheres to target language wording, translating each lexical item as target language equivalent. As the combination of the lexical item does not compose a target language equivalent $\mathrm{FE}$, this rendering is a case of foreignising strategy. The use of this strategy can be partially attributed to the low opacity of the transparent metaphor, which is literal in its verbal formulation (i.e. to put something in the) and metaphorical only in the complement of the verb (i.e. map). Secondly, a rendition of the non-metaphorical portion of the FE, in 
this case, is rather long; without the word map/mapa, source and target lines have 26 characters each. By resorting to the alternative used in the dubbed version (i.e. the use of the word historia instead of mapa), the subtitled version would not abide by the text reduction technicality. The verbal composition of this FE is not an issue in this dialogue line in dubbing. In the moment of the utterance, the character's mouth is not visible because it is turned against the wall. Therefore, there is no need to lip-sync; only a match between body movement and time of the exposure of the character in the scene is necessary. In this particular case, on the map and historia are articulated in the same moment in the film.

The FE ring a bell, in line 3, means "to cause someone to remember something or for it to seem familiar". ${ }^{12}$ The metaphor is that the sound of the ringing bell makes someone remember something or that the memory retrieved itself is the bell that rings. In any case, sound is a metaphor to memory. The dubbed version is focused on the denotative meaning of the FE. The subtitled version, however, draws on the relationship between metaphorical and literal meanings evident in the rendition. This rendition is not context-motivated, since in the film no stimulus related to sound is claimed to be the cause of any recollection. Even though the subtitled rendition's wording is not similar to source language FE, the mental image it evokes is similar to the source language metaphor. Thus, it is a case of foreignisation that is not informed by any audiovisual technicality and that imprints source language conventionalised world conceptions in the target film dialogue.

The last 2 FEs in table 4 are used in a playful way, with humorous intention and pun effect. The first of them, pain in the butt (traditionally pain in the ass) plays with the literal meaning of the string as it makes reference to a scene in the film Madagascar (2005) when the lion, Alex, actually bites the zebra Marty's bum. Non-compositionally, the FE is used as an adjective that means "a very annoying thing or person. ${ }^{13}$ In the context, the FE is used to make a double reference as to character as being someone annoying possibly because of the attack that has previously taken place in the film. The dubbed rendition retains no conventionally possibly because no target language FE would take the double literal and metaphorical connotations. In an apparent attempt to maintain the humorous play on words, the subtitled version keeps part of the source language $\mathrm{FE}$, as well as its meaning, thus adopting a foreignising strategy.

A foreignising strategy is also adopted in the subtitled versions in the last two lines in table 4. In a scene of the film Ice Age (2002), a character tries to mimic a piece of information to his companions. The word pack is repeated several times as the characters guess the mimic. After several guesses using diverse combination of words that collocate with pack, they utter the two metaphorical FEs in lines 5 and 6. In the scene, when the sabre-toothed squirrel hears the guess pack of lies, he points to the sabre-toothed cat, whom in the film tells "a completely false story, account, etc". ${ }^{14}$ Its subtitled version maintains the correspondent wording by translating "of lies" as "De mentiras". As the word pack is repeated several times before the use of the preposition $d e$ (which is used to connect two words), it makes the presence of the word bando (pack) implicit. In dubbing, the rendition 
changes the idea conveyed by the source text idiom paraphrasing it. By doing so, dubbing also erases the interplay between image and FE, suggesting that target language has no similar idiom. Conversely, subtitling borrows source language wording in the rendition in an apparent attempt to keep the play on words and image. The renditions of pack a wallop (line 6) deal with the FE in similar terms also on account of the possible lack of target language similar idiom and because of the interaction between image and words.

The tendency explored in this section is a factor that contributes to the somewhat higher proportion of foreignisation in subtitling if compared to dubbing. The FEs that dubbing domesticates compositionally and subtitling foreignises are metaphors. More specifically, all instances of compositional translations in this case seem to have been motivated by the non-availability of a FE of similar meaning in the target language, such as in the dialogue line "Any of this a-ringin' a bell?", dubbed as "Isto não te lembra alguma coisa?" (Doesn't it remind you of something?) in table 4, line 3. In sharp contrast, its subtitled version relies on the metaphorical image implied in the FE to render it as "Não soa familiar?". Furthermore, the subtitled rendition not only abides by source language conventionality, as no subtitling technicality justifies this rendition. This is one of some cases of deliberate foreignisation.

\section{Deliberate Foreignisation}

In order to investigate what contributes to the subtitling pull towards source language conventionality, the analysis carried out took into account the technicalities in audiovisual translations, the language systemic differences, and the particular contexts in which the FEs occur. However, there have been identified cases in which these parameters have proven to be insufficient to explain what might have motivated the strategies adopted to translate some of the FEs in the corpus. As the complexity inherent in any translational activity makes it feasible to acknowledge only part of a phenomenon, the renderings that could not be accounted for the listed motivational factors are here considered potentially deliberate renderings. This is the case of some renderings previously discussed, such as the subtitled versions of that's it (é isso), see you later, crocodile (see you later, crocodile), nine lives (nove vidas), look at you (olhe para você), make sure (ter certeza), putting sloths on the map (colocando as preguiças no mapa), and ringin' a bell (soa familiar). Deliberate renderings occur in subtitling only. Moreover, they occur in subtitling when the degree of retention to domestic conventionality in dubbing is higher than in subtitling. ${ }^{15}$ In other words, the instances of translation strategies that deliberately either avoid target language conventionality or present source language conventionality into translated versions of the films happen in subtitling, the final tendency identified. This tendency sheds light on the fact that subtitling distancing from domestic conventionality is partly informed by aspects beyond the immediate linguistic and technical imperatives. 


\section{Conclusion}

Considering that the corpus examined in this study is composed of films that, for their wide reception "invite the pleasures of imaginative identification" (Venuti, 1998, p. 161), audience preference for AVT method is to be considered as a factor that informs translators' decisions. In this context, O'Sullivan's (2011) remark that subtitling is often preferred "as a way of accessing another culture" (p. 104) finds echoes in Venuti's (1998) assertion that "translations allow AngloAmerican values to cultivate an elite Westernized readership" (p. 163). This fact is confirmed in the overall tendency in the corpus, whereby subtitling retains foreign conventionality more often, regardless of the nature of the FE.

Audience seek subtitled films as a means of becoming closer to the foreign nature of a film. A translated dialogue of foreignising inclination can, in its turn, be produced in order to promote hegemonic values. Consequently, deliberate foreignising translations of FEs, only identified in the subtitled films in the corpus, can be said to purposefully promote the cultivation of "Anglo-American values", including the English language. In this context, the fact that English is the world's lingua franca makes it an attractive commodity in such a way that films can be a means to learn and improve one's knowledge of the language. As the source dialogue and the subtitled version of a film are simultaneously presented, people interested in the world's lingua franca have a basis for comparison between source dialogue and translation. Open to the scrutiny of an audience not sufficiently aware of the technicalities involved in subtitling, translators might be influenced by the uninformed criticism from the audience. Ultimately, this translation method can be used as gloss for language learners.

As it follows, translators cannot be considered fully free to translate as they deem appropriate. Translators often work within an industry that shapes working conditions on behalf of maximising profit. One of the factors that distinguish dubbing and subtitling is the cost of production. As it takes more professionals to dub (i.e. translators, voice actors, directors) and equipment, it costs five to ten times higher than subtitling (Tveit, 2009). Higher investment in dubbing demands top translation quality that on its turn can be attractive to the audience; translation quality can be a risk factor in the investment. Subtitling on the other hand, due to its lower cost, might not demand such attention as a financial imperative. Additionally, as subtitlers' earnings tend to be meagre, a greater work-load can be a way to compensate and increase in income, and as a result they could be less meticulous to deal with translation challenges, such as FEs. This hypothetical, but still likely scenario, could shed light on subtitling deliberate move away from domestic conventionality. The financial imperative (one of the facets of the asymmetrical relations) that requires increased workload from the subtitler could then be a fact that motivates the tendency to avoid domestic conventionality. Adopting process-oriented approaches to the issue could enlighten the matter. 
As a result, the last of the tendencies identified helps to begin to shed light on the way translation operates to the coming about of centrifugal and centripetal forms of globalisation (Cronin, 2009). Considering the translation of FEs in the corpus of the present study, data suggest that subtitling could be more closely associated with centripetal globalisation, which is connected with imperialism and subjugation. It follows that subtitling can be a method that has the potential to reinforce the asymmetrical relations. In opposition, findings imply that dubbing can be a form of centrifugal globalisation, promoting domestic standards and retaining domestic autonomy, thus undermining the asymmetrical relations. On the basis of these findings and considering the tendencies in the strategies to translate Fes, Brazilian audience preference for dubbing could be considered a movement inwards, against the asymmetrical relations.

\section{Notes}

1. Available at http://www.thefreedictionary.com. Available at http://dictionary. cambridge.org. Available at http://www.macmillandictionary.com. Available at http://www.oxforddictionaries.com.

2. You Know. (n. d.) In Macmillan Dictionary Online. Retrieved from http://www. macmillandictionary.com/dictionary/british/know\#you-know

3. You Know. (n. d.) In Cambridge Dictionaries Online. Retrieved from http:// dictionary.cambridge.org/dictionary/learner-english/know_1?q=you+know.

4. In Fact. (n.d) In Macmillan Dictionary Online. Retrieved from http://www. macmillandictionary.com/dictionary/british/fact\#in-actual-fact.

5. That's it. (n.d) In Macmillan Dictionary Online. Retrieved from http://www. macmillandictionary.com/dictionary/british/that\#that-s-it.

6. See Your Later, Alligator (n. d.) In The Free Dictionary. Retrieved from http:// encyclopedia.thefreedictionary.com/See+You+Later+Alligator

7. Cat has nine lives (n. d.) In The Free Dictionary. Retrieved from http://idioms. thefreedictionary.com/cat+has+nine+lives.

8. Gato tem sete vidas (n. d.) In Quem Disse. Retrieved from http://quemdisse.com. $\mathrm{br} /$ frase.asp?frase $=77224$.

9. Look at you. (n. d.) In Macmillan Dictionary Online. Retrieved from http://www. macmillandictionary.com/dictionary/british/look-at\#look-at_14.

10. Make Sure. (n. d.) In Cambridge Dictionaries Online. Retrieved from http:// dictionary.cambridge.org/dictionary/learner-english/sure?q=make+sure.

11. Put on the Map. (n. d.) In Cambridge Dictionaries Online. Retrieved from http://dictionary.cambridge.org/dictionary/british/put-sth-sb-on-themap?q=put+on+the+map.

12. Ring a Bell. (n. d.) In The Free Dictionary. Retrieved from http://idioms. thefreedictionary.com/ring+a+bell.

13. Pain in the Ass. (n. d.) In The Free Dictionary. Retrieved from http://idioms. thefreedictionary.com/pain+in+the+ass.

14. Pack of Lies. (n. d.) In The Free Dictionary. Retrieved from https://www. thefreedictionary.com/pack+of+lies.

15. For more details, please refer back to the discussion related to the FEs in table 3 (lines 2 to 5 ) and in table 4 (lines 1 to 3 ). 


\section{References}

Araújo, V. L. S.(2004). Closed subtitling in Brazil. In P. Orero (Ed.), Topics in audiovisual translation. (pp. 199-212) Amsterdam/Philadelphia: John Benjamins Publishing Company.

Baker, M. (1995). Corpora in Translation Studies. An Overview and Suggestions for Future Research. Target, 7(2), 223-243.

Baker, M. (2011). In other words: A coursebook on translation. New York: Routledge.

Bellos, D. (2011). Is that a fish in your ear?: Translation and the meaning of everything. New York: Faber and Faber.

Bowker, L., \& Pearson, J. (2002). Working with specialized language: a practical guide to using corpora. New York: Routledge.

Brian \& Zuggy,T. V. (2013). SubRip (1.50b5) [Subtitle Editor]. Retrieved from http:// www.videohelp.com/tools/Subrip.

Chiaro, D. (2009). Issues in audiovisual translation. In J. Munday (Ed.) The Routledge Companion to Translation Studies (pp. 141-165). New York, NY: Routledge.

Colson, J. P. (2008). Cross-linguistic phraseological studies: An overview. In S. Granger \& F. Meunier (Eds.), Phraseology: An interdisciplinary perspective (pp. 191-206). Amsterdam: John Benjamins Publishing Company.

Cowie, A. P. (1998). Phraseology: Theory, Analysis, and Applications, New York: Oxford University Press.

Cronin, M. (2009). Globalization. In M. Baker, \& G. Saldanha (Eds.), Routledge Encyclopedia of Translation Studies (pp. 126-129). New York: Routledge.

Cronin, M. (2003). Translation and Globalization. New York: Routledge.

Danan, Martine. (1991). Dubbing as an Expression of Nationalism. Meta 36 (4): 606-614.

Davies, M. (2008-) The Corpus of Contemporary American English: 450 million words, 1990-present. Online. Available HTTP: <http://corpus.byu.edu/coca/>.

Díaz Cintas, J. \& Remael, A. (1997). Audiovisual Translation: Subtitling. Manchester: St. Jerome Publishing.

Genestreti, G. (2015). Pequisa revela que 6 em 10 brasileiros preferem filmes dublados. Retrieved July 31, 2019, from https://www1.folha.uol.com.br/ ilustrada/2015/08/1666126-pequisa-revela-que-6-em-10-brasileiros-preferemfilmes-dublados.shtml

Giddens, A. (1990). The Consequences of Modernity. Stanford: Stanford University Press.

González, L. P. (2009). Audiovisual translation. In M. Baker \& G. Saldanha (Eds.) Routledge encyclopedia of translation studies (pp. 13-20). New York: Routledge.

Lee, P. (2007). Formulaic language in cultural perspective. In P. Skandera (Ed.), Phraseology and Culture in English (pp. 471-496). Berlin: Mouton de Gruyter.

Linde, Z. de, \& Kay, N. (1999). The Semiotics of Subtitling. Manchester: St Jerome Publishing.

Luyken, G. M., \& Herbst, T. (1991). Overcoming language barriers in television: Dubbing and subtitling for the European audience (Vol. 13). European Institute for the Media.

Moon, R. (1998). Fixed Expressions and Idioms in English: A Corpus based Approach. New York: Oxford University Press. 
O'Connell, E. (1998). Choices and Constraints in Screen Translation. In L. Bowker, M. Cronin, D. Kennyand \& J. Pearson (Eds) Unity in Diversity? Current Trends in Translation Studies (pp. 65-71). Manchester: St. Jerome Publishing.

O'Sullivan, C. (2011). Translating popular film. Basingstoke: Palgrave Macmillan.

Pavesi, M. (2008). Spoken language in film dubbing: Target language norms, interference and translational routines. In D. Chiaro, C. Heiss \& C. Bucaria (Eds.) Between text and image: updating research in screen translation (pp. 79-110), Amsterdam/Philadelphia: John Benjamins Publishing Company.

Shochat, E., \& Stam, R. (1985). The cinema after Babel: language, difference, power. Screen, 26(3-4), 35-58.

Shuttleworth, M \& Cowie, M. (1997). Dictionary of translation studies. Manchester: St. Jerome Publishing.

Spiridonov, A. (2013). Subtitle Workshop (6.0b) [Subtitle Editor]. Retrieved from http://subworkshop.sourceforge.net/.

Tagnin, S. E. O. (2005). O jeito que a gente diz: expressões convencionais e idiomáticas. São Paulo: Disal Editora.

Tveit, J. E. (2009). Dubbing versus subtitling: Old battleground revisited. In J. Díaz Cintas \& G. Anderman (Eds.) Audiovisual Translation: Language Transfer on Screen (pp. 85-96), Basingstoke: Palgrave Macmillan.

Venuti, L. (1995). The translator's invisibility: A history of translation. New York: Routledge.

Venuti, L. (1998). The Scandals of Translation. New York: Routledge.

Wray, A. (2009). Formulaic language. In J. L. Mey (Ed.) Concise Encyclopedia of Pragmatics (pp. 265-271). Oxford: Elsevier.

\section{Films}

Darnell, E. (Director). (2005). Madagascar [DVD]. USA: Dreamworks. Wedge, C. (Director). (2002). Ice Age [DVD] USA: 20th Century Fox Home Entertainment. 